\title{
筑信息技术源泉 引汨汨语流
}

\author{
袁晓春 \\ 山东省威海市鲸园小学 \\ DOI:10.32629/er.v3i8.3084
}

\begin{abstract}
[摘 要] 这是一个不平凡的新年, 过年总是意味着成长。今年我们的成长收获是责任、担当与自律。疫 情阻隔了面对面的教与学,却不能阻隔一颗颗胸怀大爱,怀揣理想的心。非常时期停课但不停学。

[关键词] 小学英语; 线上教学; 信息技术

中图分类号: G623.31 文献标识码: A
\end{abstract}

为了让鲸园学子们即使宅在家里, 也能轻松读好英语, 练好英语, 领导及老 师们汇集网络,通过各种形式多次的教 研, 依据各年级的知识水平, 我们借助 “钉钉直播课”网络平台, 运用娴熟的希 沃白板课件以及希沃授课助手评价系统, 为学生搭建了一个非常系统的学习空 间。下面与大家分享我们在线上教学中 的思考与做法。

第一阶段：开发教学资源一一促自 学 递温情

(1) 创意设计 “开学第一课”

在 “停课不停教” “停课不停研” 的 大背景下, 我们英语教师团队经常进行线 上教学研讨, 明确疫情期的课程目标, 调 研学生线上学情, 根据学生的网络学习情 况, 整合完善教学资源, 科学优化教学设 计, 创意设计出复学后 “开学第一课”。

(2) 开发制作微视频课程资源

英语组分工合作, 经过线上集体研 讨, 清晰明确课程目标, 优化设计教学活 动, 丰富互动资源, 分工各作, 开发并制 作了多节微视频课程资源, 后期推送至 “学习强国” 平台, 为鲸园学子、环翠学 子以及全国的学生们提供了优质的教学 资源。

(3) 适时推送 “一起作业” app小程序

在非常时期, 不惧 “疫” 情, 推送app 小程序激励学生在家自主学习, 多听、多 读, 并按照老师的要求每天上传录音或 视频进行打卡, 老师根据学生的实际情 况进行一对一跟踪指导传递温情。
(4)有效使用 “钉钉” 家校本功能

通过家校本发送作业, 学生及时完 成并拍照提交作业, 教师第一时间接收 作业反馈批改学生的试卷和作业, 老师 圈点勾画点评, 选出优秀作业给学生观 摩示范。

第二阶段：携信息化技术手段-一 助教学 显成效

“线上教学” 在第一阶段实施的基 础上创新进入第二阶段—— “云伙伴” 在线研讨, “线上”师生之间、生生之间 的答疑解惑, 以及互动交流, 增强了 “线 上教学” 的深度性, 提高 “线上教学” 的 学习质量 ${ }^{[1]}$ 。

\section{1 运用 “钉钉” 直播系统开展} “云伙伴”在线研讨

借助希沃白板课件展开在线研讨, 运用希沃白板 5 中的思维导图、蒙层、擦 除、放大镜、课堂游戏、英文字典、四 线三格、动画效果、板中板等功能进行 知识回顾以及练习解析。我在教授外研 社三年级下册《Module2Unit1They' re monkeys. 》一课中我是这样设计的 ${ }^{[3]}$ 。

首先, 通过思维导图让学生能够非常 清晰地明确本课应该掌握的重要知识点。 其次, 在授课过程中, 运用英文字典、四线 三格、课堂游戏、擦除、蒙层、以及笔的 功能, 针对本课知识点进行细致的讲解, 学生在电脑端可以非常清晰地看到老师 的课件知识点讲解, 圈点勾画功能虽小, 但是能够对重点难点的教学目标进行有 针对性的学习, 学生一目了然。
同时在授课过程中我们也会及时根 据学生的情况, 给予及时的课堂小测反 馈, 如本课重点单词以及句型的朗读以 及本课的堂小测, 都可以通过与学生互 动连麦进行新知的检测, 及时发现学生 对知识点掌握的正确与否, 进行圈点勾 画易错题解析讲解。在此过程中我们结 合在平时教学中应用的班级优化大师, 给予学生及时的有效的课堂评价, 作为 学生平时表现的评价标准。最后, 在授 课过程中已经清楚地了解了学生对于 知识点的掌握情况, 根据这个情况我们 可以创建练习题, 并发布家校本, 让学 生自主完成并拍照上传, 老师根据学生 的练习情况进行及时的批改, 并进行一 对一反馈。

\section{2 制定 “学习小达人” 评选方案}

依据学生每日课时完成质量、每次 “云伙伴” 在线研讨参与质量 (含连麦积 极回答问题质量以及班级优化大师对学 生的评价统计)、每次单元检测质量、每 次专项检测质量, 以及开学后综合检测 质量进行综合评定。通过制定学习小达 人的评选方案, 大大地激发了学生参与 学习的积极性, 让孩子们自主地进行高 效学习, 为培养学生的自主学习习惯起 到了推动作用。

\section{3 “云伙伴” 在线研讨成果出显}

通过第二阶段的 “云伙伴” 在线研 讨这个平台, 我们用心指导了学生有效 的学习方法, 极大地调动了学生自主学 习的积极性。 


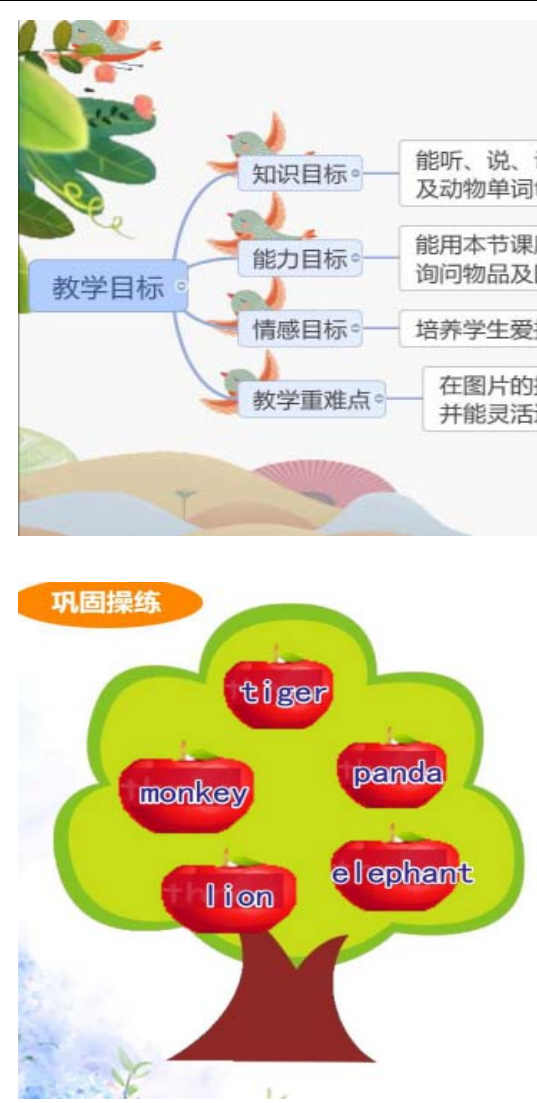

3. 1 自主阅读绘本

课上我们根据绘本主题从阅读目 标、阅读方法、阅读任务等方面推出具 体的阅读指导方案, 给学生具体有效的 阅读指导。鼓励学生根据自己水平选择 自己喜欢的绘本在家阅读, 提高语言信 息量, 养成阅读好习惯。同学们在阅读中 增加了语言信息量, 阅读素养和口语表 达能力也都有了一定的提高 ${ }^{[2]}$ 。

\section{2绘本创编}

课上鼓励学生开展丰富的想象, 课 后进行自己创编英语故事、对阅读过的 fighting. China is fighting. China will win.

以“我是冠状病毒, 侵害了武汉人民, 最终被医务人员消灭” 为故事情节制作 绘本, Come on China! You' re the best. 鼓舞中国人民坚定必胜的信心。5.3苗峻 怡创编的与病毒抗争的英文绘本。

\section{3 家长助力}

通过 “云伙伴” 线上研讨以及家校 本的及时反馈, 家长能够在线上非常清 楚孩子的学习情况, 因此家长们也加入 到陪伴孩子阅读绘本、练习口语当中, 进而帮助孩子们开阔视野, 积蓄力量。

英国浪漫主义诗人雪莱的《西风颂》 中“If Winter comes, can Spring be far behind?”（如果冬天来了, 春天还会远 吗? ) 没有一个冬天不会过去, 没有一个 春天不会到来。今天发生的一切, 都是孩 子们成长的起点和契机。只要我们坚定 信心, 守望相助、共克时艰, 必将迎来阳 光普照, 春暖花开。

\section{[参考文献]}

绘本或是针对预习过的课文中的主题对 话进行改编或续编。疫情期间, 我们虽不 能身赴武汉, 但是我们心系武汉, 于是孩 子们用自己的手中的笔为武汉祈福, 为 武汉加油!

学生结合当前疫情创编了一个非常 有创意的绘本故事: 她喜欢的小狗 “huhu” 喜欢出去玩, 但是因为当前冠状 病毒她不能陪伴它, 呼吁大家一定要做 到:

We must wear masks when we go out. 让我们一起坚定信心: Wuhan is
[1]刘粀.信息化学习资源在小学英 语教学中的利用研究 [J]. 中国新通 信,2020,22(03):199.

[2]马文璇. 谈英语绘本在小学英语 教学中的运用[J].才智,2020,(15):77.

[3]朱引霞.浅析小学英语教学中的情 境教学创设法[J]. 学周刊,2020,(03):112.

\section{作者简介:}

袁晓春(1979--), 女, 汉族, 黑龙江人, 职称二级教师, 学位文学学士, 研究方 向：信息技术与学科整合。 